Objectives: To determine the factors associated with radiographic hip involvement and its prevalence.

Methods: A cross-sectional study was performed based on patients with AS, excluding the patients with associated psoriasis or inflammatory bowel disease. To assess radiographic hip involvement, we scored the last anteroposterior pelvic radiograph performed using the Bath Ankylosing Spondylitis Radiology Index (BASRI). Demographic, clinical, laboratory and radiographic data were collected and analysed. We considered the presence of hip disease with a BASRI-hip grade of at least 2. Statistical analysis: A descriptive study was performed. To compare differences we used a 1-way ANOVA test and Pearson chi-square. The statistical analyses were done using SPSS 24.0. $p \leq 0.05$ was considered statistically significant.

Results: 215 patients were identified, with a mean age of $52 \pm 13.6$ years and $76.7 \%$ of the patients were male. The age at onset was $25.29 \pm 8.22$ years. $86.4 \%$ of the patients were HLA-B27-positive. Regarding their treatment, $27.9 \%$ were under biological therapy. A hip replacement was needed in 14 patients $(0.7 \%)$, with 6 of them requiring a bilateral hip replacement. The mean BASDAI score, BASFI score and ASDAS CRP index were $4.01 \pm 6.31 ; 4.73 \pm 8.8$ and $2.17 \pm 1.01$ respectively.

The table shows the comparison between the two groups based on the presence of hip involvement (BASRI hip $>2$ ). Statistically significant differences were observed in the age, age at onset and presence of peripheral arthritis. Patients with hip involvement had higher scores in BASFI score, ASDAS CRP and ESR. Axial radiographic involvement assessed with axial BASRI score and total SASSSm was associated with hip disease and a significant association was seen between hip involvement and metrological parameters.

\begin{tabular}{lccc}
\hline & No hip disease & Hip disease & P-value \\
& $\mathrm{n}=154(71.6 \%)$ & $\mathrm{n}=61(29.4 \%)$ & \\
\hline Age $^{*}$ (years) & $49.5 \pm 13.63$ & $58.16 \pm 11.53$ & $<0.001$ \\
Age at onset $^{*}$ (years) & $26.14 \pm 8.4$ & $23.16 \pm 7.38$ & 0.017 \\
Male sex, $\mathrm{n}(\%)$ & $113(73.4)$ & $52(85.2)$ & 0.063 \\
HLAB27+, $\mathrm{n}(\%)$ & $132(85.7)$ & $52(85.2)$ & 0.790 \\
Peripheral arthritis, $\mathrm{n}(\%)$ & $33(21.4)$ & $25(41.0)$ & 0.004 \\
Uveitis, $\mathrm{n}(\%)$ & $40(26.0)$ & $13(21.3)$ & 0.475 \\
Biological treatment, $\mathrm{n}(\%)$ & $41(27.0)$ & $19(31.1)$ & 0.54 \\
BASDAI $^{*}$ & $3.84 \pm 7.29$ & $4.47 \pm 2.14$ & 0.527 \\
BASFI $^{*}$ & $3.79 \pm 7.15$ & $7.23 \pm 11.81$ & 0.012 \\
ASDAS CRP $^{*}$ & $2.07 \pm 1.01$ & $2.45 \pm 0.95$ & 0.014 \\
ASDAS ESR $^{*}$ & $1.89 \pm 0.90$ & $2.52 \pm 1.92$ & 0.002 \\
Schober's index $^{*}(\mathrm{~cm})$ & $3.61 \pm 1.55$ & $2.43 \pm 1.69$ & $<0.001$ \\
Chest expansion $^{*}(\mathrm{~cm})$ & $4.97 \pm 1.84$ & $3.67 \pm 2.02$ & $<0.001$ \\
Cervical rotation $^{*}(\mathrm{~cm})$ & $72.03 \pm 19.73$ & $49.18 \pm 28.01$ & $<0.001$ \\
Lateral flexion $^{*}(\mathrm{~cm})$ & $12.96 \pm 5.18$ & $7.85 \pm 4.1$ & $<0.001$ \\
Occiput to wall distance $^{*}(\mathrm{~cm})$ & $2.49 \pm 4.36$ & $8.45 \pm 8.38$ & $<0.001$ \\
Intermalleolar $^{*}(\mathrm{~cm})$ & $100.22 \pm 21.22$ & $82.37 \pm 17.91$ & $<0.001$ \\
Axial BASRI $^{*}$ & $5.31 \pm 3.10$ & $8.53 \pm 3.38$ & $<0.001$ \\
Total SASSSm $^{*}$ & $10.24 \pm 16.07$ & $30.67 \pm 27.31$ & $<0.001$ \\
\hline
\end{tabular}

*Mean \pm SD.

Conclusions: Radiographic hip involvement assessed with BASRI score is prevalent and it is related with the age at onset, disease activity and the presence of peripheral arthritis. These patients present more disability, less mobility and greater axial radiographic involvement.

Disclosure of Interest: None declared

DOI: 10.1136/annrheumdis-2017-eular.4375

\section{FRI0469 DIFFERENCES BETWEEN ANKYLOSING SPONDYLITIS PATIENTS WITH AND WITHOUT RADIOGRAPHIC HIP INVOLVEMENT IN CHINA}

X. Zheng, Q. Wei, J. Gu. Department of Rheumatology and Immunology, The Third Affiliated Hospital of Sun Yat-sen Universiy, GuangZhou, China

Background: Hip involvement, defined by clinical examination or imaging techniques, is a problem of great concern in Ankylosing Spondylitis (AS) patients as it leads to functional impairment and poor outcomes. It has been shown that early age at disease onset, peripheral manifestation and severe axial disease are risk factors, but other characteristics do not show consistency through studies and data is scarce so far.

Objectives: We aim to describe the phenotype differences between AS patients with and without radiographic hip involvement and to identify potential risk factors for hip involvement.

Methods: AS patients fulfilling the Modified New York Criteria and whose pelvic Xrays have been assessed by at least one radiologist and one rheumatologist were included. Radiographic hip involvement was defined by features of osteophytes around the femoral neck, erosions of the acetabulum, axial migration of the femoral head or hip joint space narrowing. The medical records were retrospectively reviewed and collected. Demographic and disease characteristics were compared by descriptive and bivariate statistics using SPSS v19.0 and stata v12.1 package. Results: Totally 261 AS patients with hip involvement and 429 patients without hip involvement were analyzed. Statistical significance were found between these 2 groups regarding age at disease onset, gender, BMI, disease duration and presence of peripheral arthritis, with all $p$ value $\leq 0.001$. Male patients showed strong risk effect on hip involvement with the odds ratio (OR) around 3.27.
Meanwhile, the hip-involved group had lower body mass index (BMI), which may relate to long disease duration or high inflammation level. No significant difference of HLA-B27 positivity, family history and other factors were observed (Table 01). Binary logistic regression results showed that age at disease onset, gender, BMI and disease duration were associated with hip involvement in AS $(p<0.001)$. As for the symptoms, among 69 hip-involved and 75 non-involved AS with corresponding records, $83 \%$ hip-involved and 35\% non-hip-involved patients complained of typical inguinal pain $(\mathrm{OR}=8.95,95 \% \mathrm{Cl}=3.85 \sim 21.37, \mathrm{p}<0.001)$.

Table 1

\begin{tabular}{lccc}
\hline & $\begin{array}{c}\text { AS with hip involvement } \\
(\mathrm{n}=261)\end{array}$ & $\begin{array}{c}\text { AS without hip involvement } \\
(\mathrm{n}=429)\end{array}$ & $p$ value \\
\hline Age, $\mathrm{m}(\mathrm{SD})$ & $28.57(8.66)$ & $28.01(8.53)$ & 0.41 \\
Age at disease onset, $\mathrm{m}(\mathrm{SD})$ & $18.28(5.74)$ & $22.31(6.87)$ & $<0.001$ \\
Men, $\mathrm{n}(\%)$ & $240(91.95)$ & $336(77.78)$ & $<0.001$ \\
BMI, m (SD) & $20.35(3.47)$ & $21.31(3.30)$ & $<0.001$ \\
Disease duration, median & & & \\
$\quad$ (interquartile range) & $108.00(120.00)$ & $48.00(72.00)$ & $<0.001$ \\
HLA-B27 positive, $\mathrm{n}(\%)$ & $230(90.20)$ & $370(88.94)$ & 0.61 \\
Family history positive, $\mathrm{n}(\%)$ & $72(27.80)$ & $100(23.53)$ & 0.22 \\
Inflammatory low back pain, $\mathrm{n}(\%)$ & $235(90.38)$ & $381(88.81)$ & 0.52 \\
Peripheral arthritis, $\mathrm{n}(\%)$ & $118(45.21)$ & $140(32.86)$ & 0.001 \\
Dactylitis, $\mathrm{n}(\%)$ & $9(3.45)$ & $9(2.10)$ & 0.28 \\
Uveitis, $\mathrm{n}(\%)$ & $28(10.73)$ & $48(11.21)$ & 0.84 \\
Enthesitis, $\mathrm{n}(\%)$ & $56(21.62)$ & $89(21.04)$ & 0.86 \\
Axial pattern, $\mathrm{n}(\%)$ & $249(58.04)$ & 0.056 \\
\hline
\end{tabular}

Conclusions: Compared to AS patients without hip involvement, the radiographic hip-involved group are younger age at disease onset, more frequently men and complaining of typical inguinal pain, have lower BMI and longer disease duration. AS patients having these concomitant risk factors should undergo further hip assessment in clinical practice.

References:

[1] Jeong $\mathrm{H}$, Eun $\mathrm{YH}$, Kim IY. Characteristics of hip involvement in patients with ankylosing spondylitis in Korea. Korean J Intern Med. 2017 Jan;32(1):158-164.

[2] Vander Cruyssen B, Vastesaeger N, Collantes-Estévez E. Hip disease in ankylosing spondylitis. Curr Opin Rheumatol. 2013 Jul;25(4):448-54.

Disclosure of Interest: None declared

DOI: 10.1136/annrheumdis-2017-eular.4159

\section{FRI0470 CIGARETTE SMOKING HAS A DOSE-DEPENDENT RELATIONSHIP WITH DISEASE ACTIVITY AND CORRELATES WITH MORE FUNCTIONAL LIMITATION AND WORSE HEALTH ASSESSMENT IN THE PATIENTS WITH ANKYLOSING SPONDYLITIS}

Y. Jiang, Z. Liao, Z. Lin, M. Yang, Y. Zhang, Q. Li, J. Gu. Rheumatology, the Third Affiliated Hospital of Sun Yat-sen University, Guangzhou, China

Background: Ankylosing spondylitis (AS) is a chronic inflammatory disease that mainly affects the axial skeleton by causing inflammatory and osteoproliferative changes in the sacroiliac joints and spinal structures [1]. Cigarette smoking is associated with poor outcome in patients with established and early AS [2].

Objectives: Our study was to investigate the relationship between cigarette smoking and pain, disease activity, functional limitation, and health assessment in Chinese patients with AS.

Methods: Patients with AS ( $n=683$ ) from China took part in a cross-sectional survey. Smoking status was obtained by a standardized questionnaire, involving smoking status (non-smokers, exsmokers, current smokers), the age when starting smoking, cigarette numbers a day and smoking status of family numbers. The Bath AS Disease Activity Index (BASDAI), the Bath AS Functional Index (BASFI), visual Analogue scale of pain, Health Assessment Questionnaire for Spondyloarthropathy (HAQ-S) were analyzed in terms of smoking status and relationship with pack-year history.

Table 1. Demographic features and clinical and laboratory results of the patients with AS and comparison between patients with different smoking status

\begin{tabular}{|c|c|c|c|c|c|c|c|}
\hline Variable & $\begin{array}{l}\text { All patients } \\
\mathrm{N}=683\end{array}$ & $\begin{array}{c}\text { Non-smokers } \\
\quad \mathrm{N}=407\end{array}$ & $\begin{array}{l}\text { Ex-smokers } \\
\qquad \mathrm{N}=108\end{array}$ & $\begin{array}{c}\text { Current } \\
\text { smokers } \\
N=168\end{array}$ & $P(1: 3)$ & $P(2: 3)$ & $P(1: 2)$ \\
\hline Age () & $27.33 \pm 8.67$ & $26.04 \pm 8.65$ & $27.65 \pm 8.74$ & $30.24 \pm 7.98$ & 0.000 & 0.001 & 0.069 \\
\hline $\begin{array}{l}\text { Disease duration } \\
\quad \text { (years) }\end{array}$ & $0.47 \pm 0.47$ & $0.13 \pm 0.00$ & 0.0110 .04 & 0.0017 .00 & 0.000 & 0.094 & 0.071 \\
\hline Morning stiffness & & & & & & & \\
\hline & & & & & 0.000 & 0.003 & 0.739 \\
\hline Overal & $3.97 \pm 2.77$ & $3.78 \pm 2.83$ & $3.96 \pm 2.70$ & $4.44 \pm 2.61$ & 0.005 & 0.150 & 0.440 \\
\hline Noctur & & & & & & & \\
\hline & $93 \pm 2.96$ & 2. & $2.89 \pm 2.73$ & $3.68 \pm 3.11$ & 0.000 & 0.049 & 0.216 \\
\hline ESR ( & $20.94 \pm 21.71$ & $20.80 \pm 22.61$ & $19.65 \pm 20.92$ & $22.11 \pm 19.98$ & 0.311 & 0.150 & 0.407 \\
\hline $\mathrm{CRP}(\mathrm{mg} / \mathrm{dl})$ & $18.4 \pm 26.01$ & $17.33 \pm 28.14$ & $18.4 \pm 22.76$ & $20.98 \pm 22.26$ & 0.001 & 0.126 & 0.340 \\
\hline BASDAI & $3.36 \pm 2.03$ & $3.21 \pm 2.05$ & $3.30 \pm 1.79$ & $3.76 \pm 2.07$ & 0.002 & 0.065 & 0.437 \\
\hline BASFI & & & & & 0.018 & 0.379 & 0.251 \\
\hline HAQ & $0.21 \pm 0.33$ & $0.20 \pm 0.33$ & $0.19 \pm 0.30$ & $0.23 \pm 0.33$ & 0.130 & 0.313 & 0.213 \\
\hline
\end{tabular}

$P(1: 3)$ refers to $p$ value of the The Mann-Whitney $U$ test and test between non-smokers and current smokers. 
Results: Of all the 683 patients, 168 are current smokers, while 108 were ex-smokers and 407 patients never smoked. Mean scores of degree and duration of morning stiffness, overall pain, nocturnal back pain, overall back pain, CRP, BASDAI and BASFI score were all higher in the current smoker group compared to those who had never smoked $(P<0.05)$. In Spearman correlation analysis, pack years of smoking in current smokers were significantly associated with disease duration, morning stiffness (VAS) and duration, nocturnal back pain, overall back pain, CRP, and BASDAI $(P<0.01)$, and overall pain, BASFI and HAQ-S $(P<0.05)$. Conclusions: Cigarette smoking has a dose-dependent relationship with disease activity and correlates with more functional limitation and worse health assessment in patients with AS.

References:

[1] Braun, J. and J. Sieper, Ankylosing spondylitis. Target treatment criteria. Z Rheumatol, 2009. 68(1): p. 30-6.

[2] Ward, M.M., et al., Risk factors for functional limitations in patients with long-standing ankylosing spondylitis. Arthritis Rheum, 2005. 53(5): p. 710-7. Acknowledgements: None.

Disclosure of Interest: None declared

DOI: 10.1136/annrheumdis-2017-eular.2045

\section{FRI0471 PSYCHOLOGICAL DISORDERS, SLEEP DISTURBANCE AND STRESSFUL LIFE EVENTS IN THE PATIENTS WITH ANKYLOSING SPONDYLITIS}

Y. Jiang, M. Yang, Y. Zhang, Z. Liao, Z. Lin, Q. Lv, J. Qi, Q. Wei, S. Cao, J. Gu. Rheumatology, the Third Affiliated Hospital of Sun Yat-sen University, Guangzhou, China

Background: Ankylosing spondylitis (AS) is a chronic inflammatory rheumatic disease that may result in pain, functionally limitation and even less life expectancy. Psychological symptoms not only have a substantial negative impact on the quality of life, but also on the course and outcome of the chronic disorder [1]. AS patients may also suffer from various sleep problems, and pain intensity, anxiety, and depression correlated significantly with poorer sleep quality [2]. Stressful life events have a substantial association with psychological disorders, and there is some evidence indicating that even early life stress constitutes a major risk factor for the subsequent development of mental disorder [3].

Objectives: Our study was to investigate psychological disorders, sleep disturbance and stressful life events in Chinese patients with AS, and to assess the correlation between each two disorders.

Methods: AS patients diagnosed with the modified New York criteria for AS were enrolled from several provinces all over China. Participants were required to complete a set of questionnaires and examinations, including demographic and clinical information, Zung self-rating anxiety scale (SAS), Zung self-rating depression scale (SDS), the Social Readjustment Rating Scale (SRRS) and the Pittsburgh Sleep Quality Index questionnaire (PSQI). The Statistical Package for Social Sciences (SPSS) software version 21 was used for all data management and analysis. The relations between psychological variables, stressful life events, sleep quality and other parameters were examined with Spearman correlation analysis.

Results: Of all the 2772 AS patients, $79.1 \%$ were male patients. $79.5 \%$ were employed. $48.4 \%$ were married. Mean age was $28.99 \pm 8.87$. Mean disease duration was $6.84 \pm 6.78$. Mean SAS score was $49.32 \pm 18.75$. $31.6 \%$ of the patients had anxiety, of which $10.8 \%$ had severe anxiety. Mean SDS score was $54.97 \pm 16.67 .59 .3 \%$ had suffered from depression, of which $11.3 \%$ had severe depression. Mean PSQI score was $6.48 \pm 4.32$. 31.0\% of the patients were poor sleepers. SRRS score was $129.33 \pm 145.06 .35 .3 \%$ had stimulus of psychological and social elements (SPSE), while $14.4 \%$ came across severe SPSE. SAS scores were associated with age, age onset, SDS scores, SRRS scores positively and years of education negatively $(P<0.01)$. SDS scores were associated with age, SAS scores, SRRS scores positively and years of education negatively $(\mathrm{P}<0.01)$. SRRS scores also correlated of less sleep efficiency $(P<0.05)$.

Conclusions: A large number of AS patients were found to have anxiety, depression, sleep disturbance and stressful life events. These problems correlated with each other. Clinicians should pay more attention to psychological disorders and sleep problems in AS patients.

\section{References:}

[1] Gladis MM, Gosch EA, Dishuk NM, Crits-Christoph P (1999) Quality of life: expanding the scope of clinical significance. J Consult Clin Psychol 67: 320-331.

[2] Sayar K, Arikan M, Yontem T (2002) Sleep quality in chronic pain patients. Can J Psychiatry 47: 844-848.

[3] Gourion D (2009) Events of life and links with severe depression at different ages. Encephale 35 Suppl 7: S250-S256.

Acknowledgements: None.

Disclosure of Interest: Y. Jiang: None declared, M. Yang: None declared, Y. Zhang: None declared, Z. Liao: None declared, Z. Lin: None declared, Q. Lv: None declared, J. Qi: None declared, Q. Wei: None declared, S. Cao: None declared, J. Gu Grant/research support from: This project was supported by the National Natural Sciences Foundation of China (31070806), Clinical Subject (2007 and 2010) of Ministry of Public Health of China and from the Foundation of Guangdong province of China (2005A30801005 and 2008B080701086), State Board of Education Fund for the Doctoral (20060558046), Guangzhou Science and Technology Plan Projects (2006Z2-E0221) and 5010 Subject of Sun Yat-sen University (2009-2010)

DOI: 10.1136/annrheumdis-2017-eular.2246

\section{FRI0472 EXTRA-RHEUMATOLOGICAL FEATURES ARE FREQUENTLY ASSOCIATED WITH PERIPHERAL RHEUMATOLOGICAL FEATURES IN AXIAL SPONDYLOARTHRITIS AND INFLUENCE THE CHOICE OF THE ANTI-TNF IN DAILY PRACTICE. AN ANALYSIS OF 519 PATIENTS}

A. Moltó, A. Etcheto, L. Gossec, S. Perrot, N. Boudersa, P. Claudepierre, N. Roux, F. Berenbaum, A. Martin, L. Sparsa, P. Coquerelle, M. Soubrier, M. Dougados. Predict-SpA Study Group, Paris, France

Background: Axial involvement is the predominant feature of axSpA but both extra-articular (EAM)and peripheral manifestations (including synovitis and dactylitis) can be concomitantly observed.

Objectives: To evaluate whether the EAM are associated with peripheral rheumatological features in axSpA and whether these EAM influence the choice of the anti-TNF.

Methods: Study design: Prospective, multicenter, cross-sectional study in France (baseline visit of the Predict-SpA trial). Patients: definite axSpA according to the rheumatologist, requiring an anti-TNF. Data collected: Past or present signs/symptoms of EAM (psoriasis, uveitis and Inflammatory Bowel disease (IBD)), peripheral (arthritis, enthesitis and dactylitis) SpA features, and the anti-TNF prescribed by the treating rheumatologist (according to usual practice). Statistical analysis: the frequency of peripheral involvement and the type of anti-TNF (e.g. monoclonal antibodies vs soluble receptor) were compared in patients with versus (vs) without EAM

Results: Of the 519 patients (females: $46 \%$, age: $42 \pm 12$ years, HLA B27 positive: $65 \%$, X-Ray sacroiliitis: $56 \%$, inflammation on MRI of the sacro lliac Joint: $56 \%$ ), 386 were biologic naïve. A past history or current symptoms of psoriasis, uveitis and IBD was observed in 19\%,17\% and 5\% respectively and a past history or current symptoms of arthritis, enthesitis and dactylitis in $27 \%, 54 \%, 11 \%$, respectively

In patients with vs without psoriasis, the $\%$ of arthritis, enthesitis and dactylitis were $40 \%$ vs $25 \%(p=0.004), 67 \%$ vs $50 \%(p=0.002)$ and $18 \%$ vs $10 \%(p=0.026)$, respectively

In patients with vs without uveitis, the $\%$ of arthritis, enthesitis and dactylitis were $31 \%$ vs $27 \% \quad(p=0.445), 57 \%$ vs $53 \% \quad(p=0.200)$ and $13 \%$ vs $11 \%$ $(\mathrm{p}=0.772)$, respectively

In patients with vs without IBD, the \% of arthritis, enthesitis and dactylitis were $36 \%$ vs $27 \%(p=0.440), 68 \%$ vs $53 \%(p=0.180)$ and $21 \%$ vs $11 \%(p=0.152)$, respectively

Monoclonal antibodies were prescribed as the first biologic in 206 out of the 386 patients $(53 \%)$. This percentage was $56 \%$ vs $58 \%$ and vs $52 \%$ in patients with a current presence of psoriasis vs any history of psoriasis but currently absent and vs without any history of psoriasis, respectively; $p=0.785$. This percentage was $100 \%$ vs $n d \%(n=0)$ and vs $53 \%$ in patients with a current attack of uveitis vs any history of uveitis but currently inactive and vs without any history of uveitis, respectively; $p=0.032$. This percentage was $100 \%$ vs $50 \%(n=2)$ and vs $53 \%$ in patients with a current active IBD vs any history of IBD but currently inactive and vs without any history of IBD, respectively; $p=0.064$.

Conclusions: In this study focused on ax SpA patients, both peripheral rheumatological clinical features and EAM were frequently observed. The peripheral rheumatological manifestations were more frequently observed in case of concomitant psoriasis. Monoclonal antibodies were the preferred anti-TNF in case of a past history (even currently quiescent) of uveitis or IBD in daily practice. Acknowledgements: This study was conducted thanks to an unrestricted grant from MSD

Disclosure of Interest: None declared

DOI: 10.1136/annrheumdis-2017-eular.4713

\section{FRI0473 PATIENT-PHYSICIAN DISCORDANCE IN GLOBAL ASSESSMENT IN 401 EARLY AXIAL SPONDYLOARTHRITIS (AXSPA) PATIENTS FROM THE DESIR COHORT: WHAT IS THE EFFECT ON OUTCOMES AT 3 YEARS?}

C. Desthieux ${ }^{1}$, A. Molto ${ }^{2}$, A. Saraux ${ }^{3}$, B. Fautrel ${ }^{1}$, L. Gossec ${ }^{1} .{ }^{1}$ Rheumatology, Paris 06 University and Pitié-Salpêtrière Hospital; ${ }^{2}$ Rheumatology, Paris Descartes University and Cochin Hospital, Paris; ${ }^{3}$ Cavale Blanche University Hospital, Brest, France

Background: Discordance between patients' and physicians' ratings of disease activity is frequent. We have previously shown this discordance occurs in around $28 \%$ of visits in early axSpA though repeated discordance (over several visits) is less frequent (1).

Objectives: To assess in patients with early axSpA, the impact at 3 years of repeated discordance on treatment prescription, functional incapacity and remission.

Methods: DESIR (Devenir des Spondyloarthropathies Indifférenciées Récentes) is a French, multicenter, longitudinal cohort of patients with early inflammatory back pain suggestive of axSpA (2). Patient and physician global assessment 